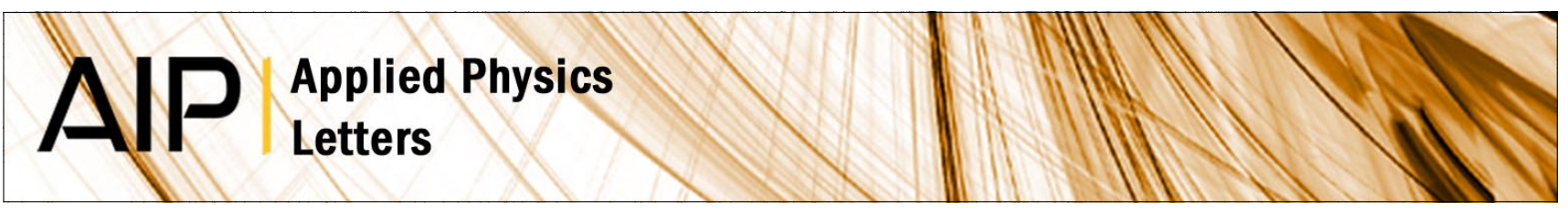

\title{
Improved performance of polymer light-emitting diodes with nanocomposites
}

A. Mohammed Hussain, B. Neppolian, Sun Hee Kim, Jin Young Kim, Hee-Chul Choi et al.

Citation: Appl. Phys. Lett. 94, 073306 (2009); doi: 10.1063/1.3086275

View online: http://dx.doi.org/10.1063/1.3086275

View Table of Contents: http://apl.aip.org/resource/1/APPLAB/v94/i7

Published by the AIP Publishing LLC.

Additional information on Appl. Phys. Lett.

Journal Homepage: http://apl.aip.org/

Journal Information: http://apl.aip.org/about/about_the_journal

Top downloads: http://apl.aip.org/features/most_downloaded

Information for Authors: http://apl.aip.org/authors

\section{ADVERTISEMENT}
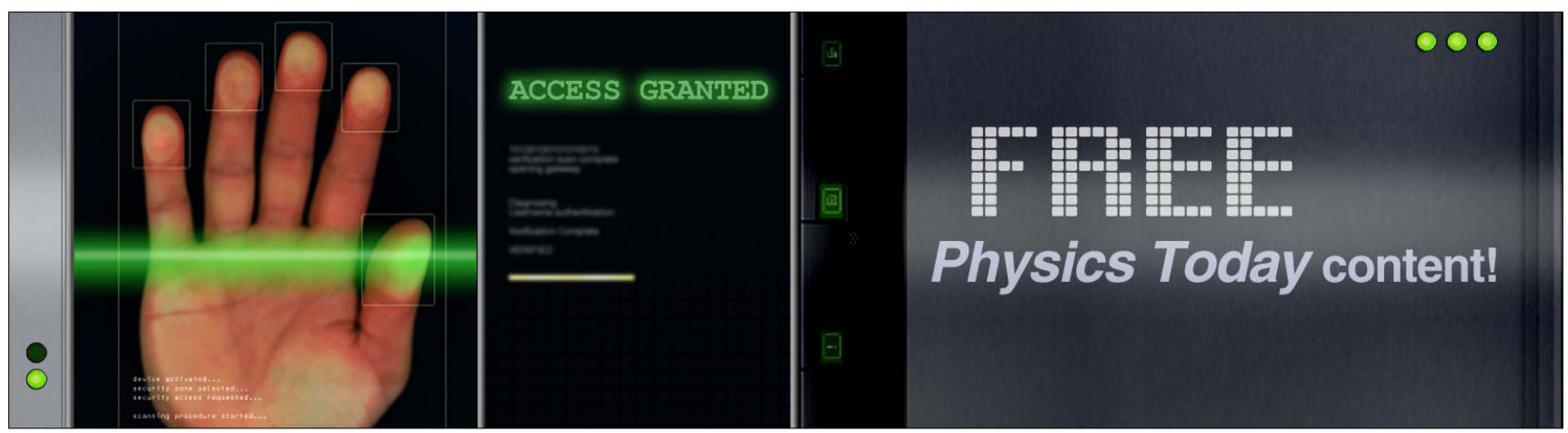


\title{
Improved performance of polymer light-emitting diodes with nanocomposites
}

\author{
A. Mohammed Hussain, ${ }^{1}$ B. Neppolian, ${ }^{2}$ Sun Hee Kim, ${ }^{3}$ Jin Young Kim, ${ }^{3, a)}$ Hee-Chul Choi, ${ }^{2}$ \\ Kwanghee Lee, ${ }^{3}$ Seong-Ju Park, ${ }^{1, b)}$ and Alan J. Heeger ${ }^{3}$ \\ ${ }_{1}^{1}$ Department of Material Science and Engineering, Gwangju Institute of Science and Technology, \\ Gwangju 500-712, Republic of Korea \\ ${ }^{2}$ Department of Environmental Science and Engineering, Gwangju Institute of Science and Technology, \\ Gwangju 500-712, Republic of Korea \\ ${ }^{3}$ Heeger Research Centre for Advanced Materials (HCAM), Gwangju Institute of Science and Technology, \\ Gwangju 500-712, Republic of Korea
}

(Received 18 September 2008; accepted 23 January 2009; published online 19 February 2009)

\begin{abstract}
The characteristics of a hybrid polymer light-emitting diode (HPLED) with an active layer of poly [2-methoxy,5-(2-ethylhexoxy)-1,4-phenylenevinylene] blended with Au-capped $\mathrm{TiO}_{2}$ nanocomposites are reported. Both the increased current in the active layer and low turn-on voltage were attributed to incorporation of $\mathrm{Au}$-capped $\mathrm{TiO}_{2}$ in the electroluminescent polymer. The maximal brightness of $11630 \mathrm{~cd} / \mathrm{m}^{2}$ was observed in HPLED with a 1:1 ratio of Au-capped $\mathrm{TiO}_{2}$. The enhanced performance was attributed to the roughness assisted charge transport induced by the Au-capped $\mathrm{TiO}_{2}$ nanocomposites in the active polymer. (C) 2009 American Institute of Physics. [DOI: $10.1063 / 1.3086275$ ]
\end{abstract}

Recent advances in organic light-emitting devices include hybrid polymer light-emitting diodes (HPLEDs), which are appropriate for use as low-power light-emitting sources in solid-state lighting systems. ${ }^{1-3}$ In the past decade, reliable organic light-emitting diodes (OLEDs) were fabricated by mechanical deposition of thin layers of metals on the device for injection of electrons in the polymer systems. ${ }^{2}$ Use of metal oxide-polymer nanocomposite structures slightly improved the charge injection in polymer lightemitting diodes. ${ }^{3}$ More recent studies of hybrid OLEDs demonstrate improved device performance due to the enhanced current injection; however, the complexity of their design prevent their commercialization. ${ }^{4}$ The mass production of OLEDs requires simplicity of design, dramatic improvement in performance, as well as easy and inexpensive processibility. Consequently, a promising solution that meets these requirements can be achieved only with a solution-processible approach $^{5}$ that uses innovative hybrid nanocomposite systems incorporated into electroluminescent (EL) polymers. Composites based on semiconductors and metals reportedly facilitates charge transport. ${ }^{6,7}$ This goal was realized by blending the electron transporting nanoparticles into luminescent polymers, thereby enhancing performance without use of complicated structures. ${ }^{8}$ The purpose of the present study was to increase the brightness of HPLED by using hybrid nanocomposite polymer systems. We employed titanium oxide $\left(\mathrm{TiO}_{2}\right)$ capped with gold $(\mathrm{Au})$, which has potential for use in energy-conversion devices. ${ }^{9}$ We synthesized $\mathrm{TiO}_{2}$ particles using the sol-gel method and capped 10-12 $\mathrm{nm} \mathrm{TiO}_{2}$ particles with the Au for efficient charge transfer in HPLEDs. The results obtained in this study show that Aucapped $\mathrm{TiO}_{2}$ nanocomposite improves the current flow and luminous efficiency of HPLEDs.

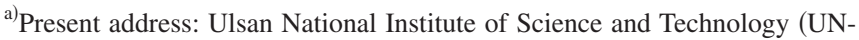
IST), Ulsan, Republic of Korea. Electronic mail: jykim@unist.ac.kr.

b) Author to whom correspondence should be addressed. Electronic mail: sjpark@gist.ac.kr.
}

$\mathrm{TiO}_{2}$ particles were synthesized using an ultrasonicassisted sol-gel method that used titanium tetra isopropoxide as the precursor. $\mathrm{TiO}_{2}$ was prepared using a bath ultrasonication method and hydrolysis of titanium isopropoxide took place under ultrasonic irradiation for $1 \mathrm{~h}$. After preparation of $\mathrm{TiO}_{2}$, the particles were maintained at room temperature for $20 \mathrm{~h}$ for slow hydrolysis. The particles were then dried at room temperature for $12 \mathrm{~h}$ and calcined at $500{ }^{\circ} \mathrm{C}$ in a furnace under continuous air flow for $3 \mathrm{~h} .{ }^{10,11}$ The preparation of Au-capped $\mathrm{TiO}_{2}$ by chemical reduction using $\mathrm{HAuCl}_{4}$ and $\mathrm{NaBH}_{4}$ has been reported previously. ${ }^{12}$ Au-capped $\mathrm{TiO}_{2}$ nanoparticles were prepared by mixing the required amounts of $\mathrm{HAuCl}_{4}$ solution and $\mathrm{TiO}_{2}$ nanoparticle suspension in water under vigorous stirring for $10 \mathrm{~min}$ to achieve strong adsorption of $\left[\mathrm{AuCl}_{4}\right]^{-}$on the $\mathrm{TiO}_{2}$ particles. Chemical reduction in $\left[\mathrm{AuCl}_{4}\right]^{-}$on the $\mathrm{TiO}_{2}$ particles was performed by drop-wise addition of a $\mathrm{NaBH}_{4}(10 \mathrm{mM})$ solution to the $\left[\mathrm{AuCl}_{4}\right]^{-} / \mathrm{TiO}_{2}$ suspension under vigorous stirring until the

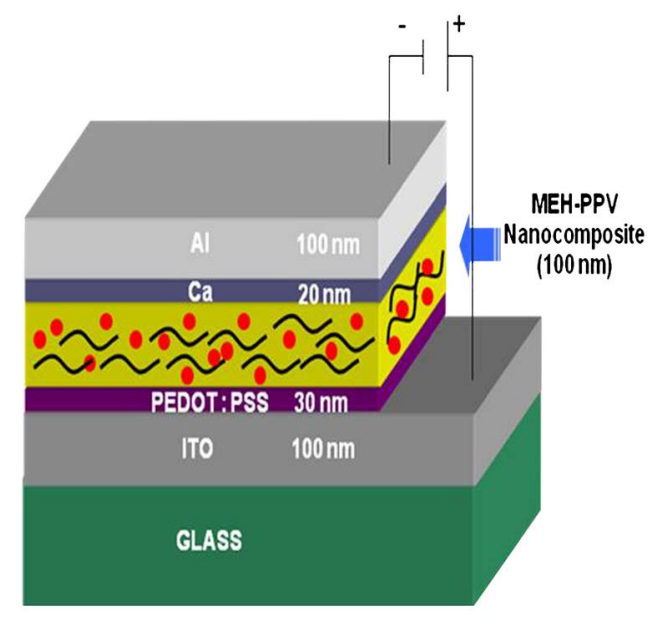

FIG. 1. (Color online) (a) Schematic diagram of the HPLED with Aucapped $\mathrm{TiO}_{2}$ nanocomposites. 

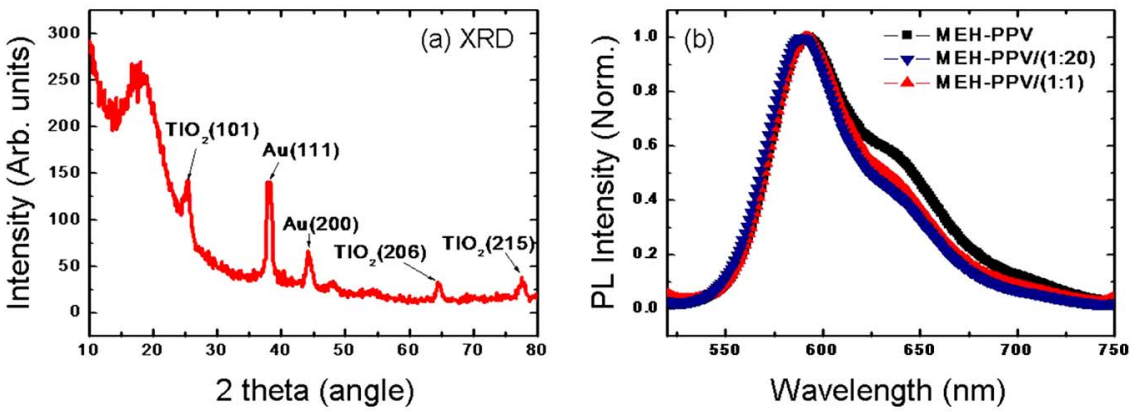

FIG. 2. (Color online) (a) XRD of Aucapped titanium oxide nanoparticles. (b) Normalized PL spectra of the HPLEDs with different nanocomposite ratios.

solution became wine-red in color. Au-capped $\mathrm{TiO}_{2}$ nanoparticles were then filtered and dried at room temperature for $12 \mathrm{~h}$.

The HPLED was fabricated by precleaning indium tin oxide (ITO) with acetone and detergent to remove the organic and other impurities. The ITO layer was then ultrasonicated using deionized water, acetone, and isopropyl alcohol, respectively, for $30 \mathrm{~min}$ each. The surface of the ITO was made hydrophilic by reactive-ion etching. Poly(3,4-ethylenedioxythiophene):poly(styrene sulfonate) (PEDOT:PSS) was coated on the transparent ITO above the glass substrate at a spin coater speed of $5000 \mathrm{rpm}$ for $40 \mathrm{~s}$. The active layer of the HPLED was prepared by blending the Au-capped $\mathrm{TiO}_{2}$ nanoparticles in the EL polymer, poly [2-methoxy, 5-(2-ethylhexoxy)-1, 4-phenylenevinylene], (MEH-PPV) at two different ratios of $\mathrm{Au}$ and $\mathrm{TiO}_{2}$, a 1:1 and 1:20 ratio of $\mathrm{Au} / \mathrm{TiO}_{2}$. The MEH-PPV polymer was dissolved in 1,2-dichlorobenzene at a concentration of $1 \mathrm{wt} \%$ along with 0.5 wt $\%$ of nanocomposite. The polymer was then dispersed by agitation for more than $12 \mathrm{~h}$ inside the glove box. The nanocomposite active layer was filtered using a $1 \mu \mathrm{m}$ filter and then spin-coated on the hole-transporting polymer PEDOT:PSS at a spin coater speed of $1500 \mathrm{rpm}$ for $60 \mathrm{~s}$ and a $\mathrm{Ca} / \mathrm{Al}$ cathode was deposited on the nanocomposite layer, as shown in Fig. 1.

Figure 2(a) shows the X-ray diffraction (XRD) curves of Au-capped $\mathrm{TiO}_{2}$ nanocomposites. The XRD peaks at (101), (206), and (215) confirm the presence of $\mathrm{TiO}_{2}$ in the nano- composite system. Moreover, Au-capping on $\mathrm{TiO}_{2}$ was evident by the presence of $\mathrm{Au}$ (111) and (200) peaks in the XRD spectrum. In addition, the (111) diffraction peak of Au superimposed with (004) peak of $\mathrm{TiO}_{2}$ due to the nanosized crystalline domains of metallic gold in the face-centered-cubic (fcc) structure. The intensities of these peaks are dependent on the composition of the metal and semiconductor. ${ }^{13}$ The photoluminescence (PL) of the MEH-PPV, as depicted in Fig. 2(b), shows the effect of incorporation of Au-capped $\mathrm{TiO}_{2}$ nanocomposite. The PL spectrum of MEH-PPV pristine film exhibited a peak at $580 \mathrm{~nm}$ along with a predominant shoulder at $635 \mathrm{~nm}$. The shoulder peaks on the PL spectra of MEH-PPV are due to the formation of interchain emissive species. However, the intensity of the shoulder peaks was reduced in the composite-polymer systems by the presence of Au-capped $\mathrm{TiO}_{2}$ in the MEH-PPV polymer. The decrease in the shoulder peak has been attributed to the solid-solution effect, which occurs when interchain interactions are reduced. ${ }^{14}$

Current-voltage $(I-V)$ characteristics of the HPLED were measured and the results are shown in Fig. 3(a). The turn-on voltage for the HPLED with a $\mathrm{TiO}_{2} / \mathrm{Au}$ ratio of $1: 1$ was approximately $2.0 \mathrm{~V}$, whereas the turn-on voltage of unmodified HPLED with only MEH-PPV as the active layer was approximately $2.5 \mathrm{~V}$. At constant voltage, the current density increased in the HPLEDs with Au-capped $\mathrm{TiO}_{2}$ nanocomposite. The luminance-voltage $(L-V)$ data depicted in Fig.
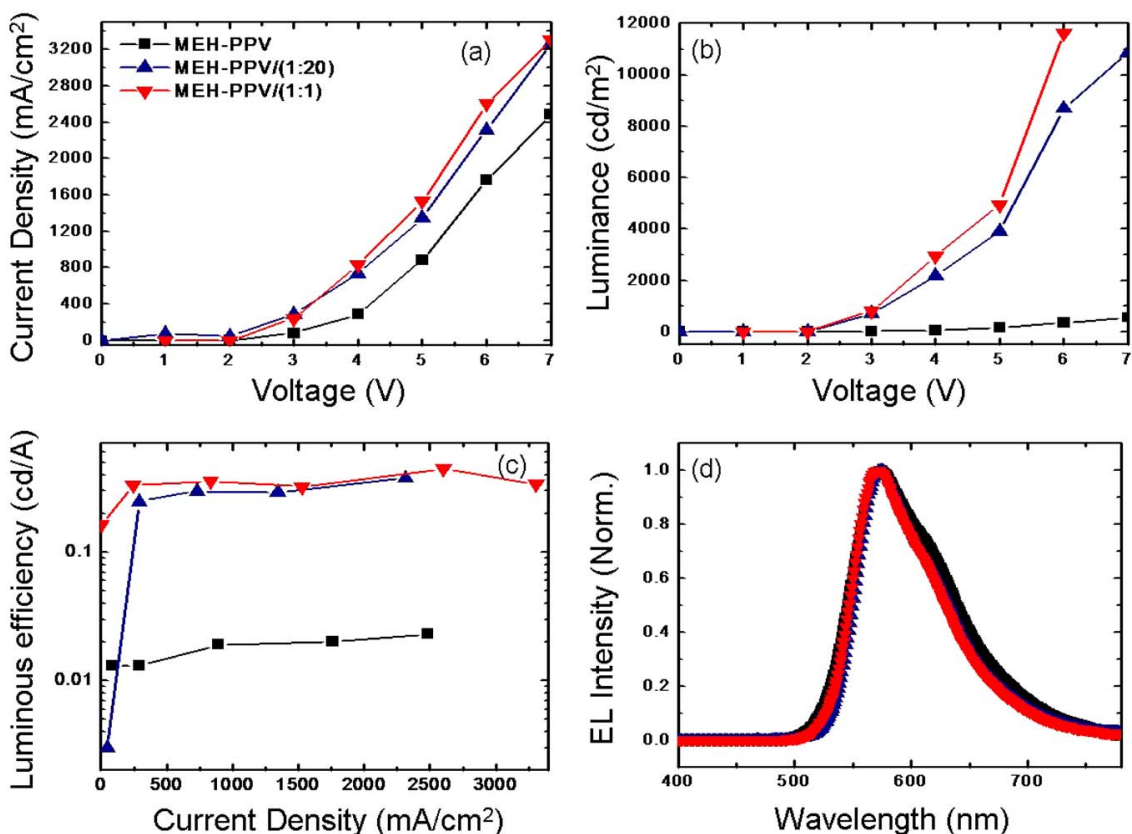

FIG. 3. (Color online) (a) Currentvoltage $(I-V)$ characteristics of HPLEDs with various nanoparticle ratios. (b) Luminance-voltage $(L-V)$ characteristics of HPLEDs with various nanoparticle ratios. (c) Comparison of luminous efficiency of HPLEDs with various nanoparticle ratios. (d) EL spectra of HPLEDs with different nanoparticle ratios. 
3(b) illustrates the results for the HPLED with Au-capped $\mathrm{TiO}_{2}$ nanocomposite with a 1:1 ratio. The maximal brightness of $11630 \mathrm{~cd} / \mathrm{m}^{2}$ was measured at $6.0 \mathrm{~V}$, along with a significant increase in current. However, HPLED with a Au-capped $\mathrm{TiO}_{2}$ ratio of 1:20 showed a brightness of $8690 \mathrm{~cd} / \mathrm{m}^{2}$ at $6.0 \mathrm{~V}$, which is lower than the luminescence of HPLED with the 1:1 ratio, as shown in Fig. 3(b). Efficiency of the HPLEDs with nanocomposites is shown in Fig. 3(c). HPLED with Au-capped $\mathrm{TiO}_{2}$ particles showed the highest luminous efficiency of $0.45 \mathrm{~cd} / \mathrm{A}$ at a current density of $2600 \mathrm{~mA} / \mathrm{cm}^{2}$. These values were greater than those measured for the device without nanocomposite, which showed a low luminous efficiency. Figure 3(d) shows the electroluminescence spectra of HPLEDs with nanocomposites. The $580 \mathrm{~nm}$ and shoulder peaks of the EL spectra of the HPLEDs with the Au-capped $\mathrm{TiO}_{2}$ nanocomposite were the same as those of the PL spectra of nanocomposite systems depicted in Fig. 2(b). This clearly shows that the PL and EL emissions share the same origin.

The AFM measurement (not shown) revealed that the MEH-PPV film with the 1:1 ratio of Au-capped $\mathrm{TiO}_{2}$ nanocomposite has the highest root-mean-square (rms) roughness of $10.2 \mathrm{~nm}$. The rougher film with 1:1 ratio of Au-capped $\mathrm{TiO}_{2}$ is due to enhanced dipole-dipole interaction of $\mathrm{Au}$ nanoparticles. Similarly, the film with the 1:20 ratio of Aucapped $\mathrm{TiO}_{2}$ showed the rms roughness of $3 \mathrm{~nm}$. For the MEH-PPV pristine film, however, the measured rms roughness was only $1.5 \mathrm{~nm}$. These results indicate that the Aucapped $\mathrm{TiO}_{2}$ nanocomposite incorporated in the EL polymer facilitates the increase in charge carriers by roughness assisted tunneling, as reported by Park et al. ${ }^{15}$ It is believed that the nanocomposite adhere to the ITO anode by electrostatic forces; thereby, the nanomorphologically roughened EL layer causes a larger interfacial contact area between the cathode $(\mathrm{Ca})$ and EL polymer that can be responsible for the enhanced electrical performance of HPLED.,16 Moreover, the nanocomposite adhered on the ITO layer behaves like field emitters and thus the charges are gathered around the sharp clusters of nanocomposite. The charges can easily tunnel into the MEH-PPV EL layer facilitating a current flow into HPLED. ${ }^{17}$ The increased charge injection in turn can enhance the electron-hole recombination and optical efficiency of the HPLED.

In conclusion, the electrical properties and luminous efficiency of the HPLED were remarkably improved by addition of Au-capped $\mathrm{TiO}_{2}$ nanocomposite to the light-emitting MEH-PPV polymer layer. The enhanced electrical and optical performances of the HPLED were attributed to the increased current through the nanomorphologically roughened surface induced by the addition of Au-capped $\mathrm{TiO}_{2}$ in the MEH-PPV layer.

This work was supported by a Korea Science and Engineering Foundation (KOSEF) grant funded by the Korea government (MOST) (Grant No. R17-2007-078-01000-0) and by the Heeger Center for Advanced Materials (HCAM).

${ }^{1}$ K. Morii, M. Ishida, T. Takashima, T. Shimoda, Q. Wang, M. K. Nazeeruddin, and M. Gratzel, Appl. Phys. Lett. 89, 183510 (2006).

${ }^{2}$ J. X. Sun, X. L. Zhu, H. J. Peng, M. Wong, and H. S. Kwok, Appl. Phys. Lett. 87, 093504 (2005).

${ }^{3}$ S. A. Haque, S. Koops, N. Tokmoldin, J. R. Durrant, J. Huang, D. D. C. Bradley, and E. Palomares, Adv. Mater. (Weinheim, Ger.) 19, 683 (2007). ${ }^{4}$ C. A. Di, G. Yu, Y. Liu, X. Xu, D. Wei, Y. Song, Y. Sun, Y. Wang, and D. Zhu, Adv. Funct. Mater. 17, 1567 (2007).

${ }^{5}$ J. Y. Kim, K. Lee, N. E. Coates, D. Moses, T. Q. Nguyen, M. Dante, and A. J. Heeger, Science 317, 222 (2007).

${ }^{6}$ V. Subramanian, E. E. Wolf, and P. V. Kamat, J. Am. Chem. Soc. 126, 4943 (2004)

${ }^{7}$ K. G. Thomas and P. V. Kamat, Acc. Chem. Res. 36, 888 (2003).

${ }^{8}$ S. A. Carter, J. C. Scott, and P. J. Brock, Appl. Phys. Lett. 71, 1145 (1997).

${ }^{9}$ D. Matthey, J. G. Wang, S. Wendt, J. Matthiesen, R. Schaub, E. Laegsgarrd, B. Hammer, and F. Benenbacher, Science 315, 1692 (2007).

${ }^{10}$ P. V. Kamat, J. Phys. Chem. C 111, 2834 (2007).

${ }^{11}$ B. Neppolian, Q. Wang, H. Jung, and H. Choi, Ultrason. Sonochem. 15, 649 (2008).

${ }^{12}$ A. Dawson and P. V. Kamat, J. Phys. Chem. 105, 960 (2001).

${ }^{13}$ P. D. Cozzoli, M. L. Curri, C. Giannini, and A. Agostiano, Small 2, 413 (2006)

${ }^{14}$ J. Liu, Y. Shi, and Y. Yang, Appl. Phys. Lett. 79, 578 (2001)

${ }^{15}$ J. H. Park, Y. T. Lim, O. O. Park, J. K. Kim, J. W. Yu, and Y. C. Kim, Chem. Mater. 16, 688 (2004).

${ }^{16}$ S. H. Wu, H. M. Huang, K. C. Chen, C.-W. Hu, C. C. Hsu, and R. C. Tsiang, Adv. Funct. Mater. 16, 1959 (2006).

${ }^{17}$ G. R. Lin, C. J. Lin, and C. K. Lin, Opt. Express 15, 2555 (2007). 